\title{
FIRST BRAZILIAN CONSENSUS ON MULTIMODAL TREATMENT OF COLORECTAL LIVER METASTASES. MODULE 1: PRE- TREATMENT EVALUATION
}

\author{
I Consenso Brasileiro de tratamento multidisciplinar de metástase hepática colorretais. Módulo 1: avaliação pré-tratamento
}

Felipe José Fernandez COIMBRA, Heber Salvador de Castro RIBEIRO, Márcio Carmona MARQUES, Paulo HERMAN, Rubens CHOJNIAK, Antonio Nocchi KALIL, Evanius Garcia WIERMANN, Sandro Roberto de Araújo CAVALLERO, Fabricio Ferreira COELHO, Paulo Henrique de Souza FERNANDES, Anderson Arantes SILVESTRINI,

Maria Fernanda Arruda ALMEIDA, Antônio Luis Eiras de ARAÚJO, Marcos PITOMBO, Heberton Medeiros TEIXEIRA,

Fábio Luiz WAECHTER, Fábio Gonçalves FERREIRA, Alessandro Landskron DINIZ, Giuseppe D'IPPOLITO,

Maria Dirlei F. de Sousa BEGNAMI, Gabriel PROLLA, Silvio Márcio Pegoraro BALZAN, Thiago Bueno de OLIVEIRA, Luís Arnaldo SZULTAN, Javier LENDOIRE, Orlando Jorge Martins TORRES

From the following Societies: International Hepato-Pancreato-Biliary Association (BRZ CHPTR) - CB-IHPBA; Brazilian Society of Surgical Oncology - SBCO; Brazilian Society of Clinical Oncology - SBOC; Brazilian College of Digestive Surgery - CBCD; Brazilian College of Surgeons CBC; American Hepato-Pancreato-Biliary Association - AHPBA, São Paulo, Brazil

HEADINGS - Colorectal cancer. Liver metastases. Brazilian consensus. Pre-treatment workout.

\section{Correspondence:}

Felipe José Fernández Coimbra

E-mail: coimbra.felipe@uol.com.br

Financial source: none

Conflicts of interest: none

Received for publication: 12/05/2015

Accepted for publication: 11/08/2015

DESCRITORES: Câncer colorretal. Metástases hepáticas. Consenso Brasileiro. Avaliação prétratamento.
ABSTRACT - Background: Liver metastases of colorectal cancer are frequent and potentially fatal event in the evolution of patients with these tumors. Aim: In this module, was contextualized the clinical situations and parameterized epidemiological data and results of the various treatment modalities established. Method: Was realized deep discussion on detecting and staging metastatic colorectal cancer, as well as employment of imaging methods in the evaluation of response to instituted systemic therapy. Results: The next step was based on the definition of which patients would have their metastases considered resectable and how to expand the amount of patients elegible for modalities with curative intent. Conclusion: Were presented clinical, pathological and molecular prognostic factors, validated to be taken into account in clinical practice.

RESUMO - Racional: As metástases hepáticas de câncer colorretal são evento frequente e potencialmente fatal na evolução de pacientes com estas neoplasias. Objetivo: Neste módulo procurou-se contextualizar esta situação clínica, bem como parametrizar dados epidemiológicos e de resultados das diversas modalidades de tratamento estabelecidas. Método: Foi realizada discussão sobre como detectar e estadiar o câncer colorretal metastático, bem como o emprego dos métodos de imagem na avaliação de resposta ao tratamento sistêmico instituído. Resultado: Fundamentou na definição de quais pacientes teriam suas metástases consideradas ressecáveis e de como se poderia ampliar a gama de pacientes submetidos às modalidades de tratamento ditas de intuito curativo. Conclusão: Foram apresentados os fatores prognósticos clínicos, patológicos e moleculares com validação para serem levados em consideração na prática clínica.

\section{INTRODUCTION}

iver metastases of colorectal cancer are frequent and potentially fatal event in the evolution of patients with these malignancies. In this module was contextualize its clinical situation, as well as parameterize epidemiological data and results of the various established treatment modalities.

\section{METHOD}

Discussion on detecting and staging metastatic colorectal cancer was performed, as well as the use of imaging methods in the evaluation of response to systemic treatment instituted.

RESULTS (CLM)

Topic 1 - Epidemiology and results of treatment in colorectal liver metastases

Colorectal cancer (CRC) ranks fourth in global statistics of cancer incidence, with approximately $1,360,000$ cases/year. With regard to mortality, it is estimated that there are over 693,000 deaths related to the disease in the world and it is the third leading 
cause of death in women and the fourth in men ${ }^{1}$. The number of new cases estimated for Brazil in 2014 was approximately 32,600 and it was the third most common cancer in men and the second among women, excluding non-melanoma skin cancers ${ }^{2}$.

Approximately half of the patients with CRC develop metastases during their lives $3,4,5,6,7,8$. The most common site of metastatic CRC is the liver, occurring in $80 \%$ of cases $^{8,9,10,11,12,13}$, representing approximately half of all patients with $C R C^{3,4,5,6,7,8}$ and as the single site of metastasis in 20 to $50 \% 14,15,16$; however, only 15 to $30 \%$ are candidates for resection ${ }^{12,13,17}$.

In population studies, the frequency of synchronous liver metastases from colorectal cancer CLM varies from 14.5 to $24 \% 8,12,14,18,19,20,21$. In a French population-based study with 24 years of follow-up of patients diagnosed with CRC, there was stability in the diagnosis of synchronous CLM during the period with crude incidence calculated at $11.3 / 100,000$ for men and 6.9/100,000 for women, age-adjusted incidence at $7.6 / 100,000$ and $3.7 / 100,000$ respectively ${ }^{8}$.

The frequency of metachronous CLM is highly variable in the literature, arising from database differences and diversity of definitions. In prospective and retrospective studies of referral centers, this rate reaches $35 \%^{22,23,24}$. In observational prospective studies and population studies, this frequency is lower, ranging from 5.7 to $16.3 \% 8,14,18,19,23$. A majority of CLM occurs in the first three years $8,14,16,18,19$. The incidence of CLM is approximately $4.3 \%$ at one year, $8.7 \%$ at two years, $12 \%$ at three years and $16.5 \%$ at five years after resection ${ }^{8,18}$.

An interesting point to note is that the incidence of CLM may be lower in patients with chronic liver disease such as steatosis ${ }^{25}$, virus $B$ hepatitis and virus $C$ hepatitis $26,27,28$. In a meta-analysis of observational studies, there was a lower incidence of $C L M(O R=0.26$ [0.18 to 0.38$] ; p<0.0001)$ in patients with chronic liver disease 29 .

Attention must be paid to the fact that there are no specific Brazilian epidemiological studies to determine the proportion of patients with CRC who develop liver metastases. In addition, the Brazilian National Cancer Institute (INCA) estimates may be underestimated because of underreporting, besides the fact that data are collected only in some reference centers in Brazil, not representing the entire population.

Emphasizing the observation above, a tentative estimate made for the Brazilian population based on the incidence rates supplied by INCA for colorectal cancer in 2014, which is 32,600 new cases/year, one can suppose that around 16,300 (50\%) patients have or will have CLM, of which 2,445 to 4,890 patients/year (15 to $30 \%$ ) will be potential candidates for liver resections.

Various modalities, either isolated or associated, can be used in the treatment of liver metastases. Liver resection showed benefit compared to unresectable patients, with 5 -year overall survival of $55.2 \%$ versus $19.5 \%$ and a median overall survival of 65.3 months versus 26.7 months, respectively ${ }^{30}$ Unfortunately, recurrence rates after surgery can reach up to $70 \%$ of cases $^{31,32}$.

Looking at the same resectable metastases, a study by the European Organization for Research and Treatment of Cancer (EORTC) evaluated the role of chemotherapy with perioperative FOLFOX4 regimen. This study showed an absolute increase in progression-free survival of $8.1 \%$ (33.2\% vs. $42.4 \%$, HR: $0.77, p=0.041$ ) in eligible patients, with a greater number of complications for the group submitted to chemotherapy ${ }^{32}$.

Other studies had the aim to show the benefit of adjuvant chemotherapy after resection. A meta-analysis encompassing three randomized clinical studies confirmed a gain in progressionfree survival and disease-free survival, but benefit in overall survival was not reached ${ }^{33}$

However, in the setting of unresectable metastatic disease, chemotherapy has an unquestionable role. Studies have evaluated its role (without monoclonal antibody) and found a conversion rate for resectable tumors of approximately $13.5 \%{ }^{34}$. Additionally, in tumors that became resectable, the 5 -year survival was between $23 \%$ and $35 \% 34,35,36$, and 10 year survival around $27 \%{ }^{35}$. When we add more drugs to the chemotherapy regimen, as in the FOLFOXIRI regimen, the conversion rate was increased to $36 \%$, accompanied by median overall survival of 22.6 months ${ }^{37}$.

In this same scenario of unresectable metastatic disease, cetuximab was evaluated when associated with the FOLFIRI or FOLFOX regimen. The resectability of liver lesions was achieved in $38 \%$ of patients. In addition, in a retrospective analysis of KRAS status, the resection rate increased to $60 \%$ in patients with wild-type KRAS treated with cetuximab ${ }^{38}$. In another study with only FOLFOX associated with or not with cetuximab, the overall and median 5 -year survival was $30 \%$ and 24.4 months, respectively, with a complete resection rate of $25.7 \%$. The median survival in patients undergoing complete resection was 46.4 months $^{39}$. Studies with panitumumab showed similar results with median overall survival not yet reached in patients with complete resection ${ }^{40}$. More recent Phase II studies evaluating the role of targeted therapy, without restricting metastasis sites, showed median overall survival of 25 to 29.9 months ${ }^{41,42}$

Another monoclonal antibody, not taking into account the RAS status, is bevacizumab, an antibody that binds to circulating VEGF-A increasing the efficacy of any cytotoxic active regimen ${ }^{43}$. First-line use showed an increase in overall and progression-free survival and response rate when combined with $5 \mathrm{FU} /$ /eucovorin / irinotecan ${ }^{44,45}$ or only $5 \mathrm{FU} /$ /eucovorin ${ }^{45}$ or capecitabine ${ }^{46,47}$. Combining oxaliplatin also showed an increase in progression-free survival ${ }^{48}$. The combination with FOLFOXIRI showed better progression-free survival and response rate, with one of the longest survival rates that has been reported so far in this scenario ${ }^{49}$.

To understand the impact of liver metastases in patient survival, we can make a non-ideal comparison between the above studies presented and those that evaluated the role of the same treatments in non-metastatic disease, especially in patients with stage III tumors. Survival rates vary from $47 \%$ at three years when only surgery is offered ${ }^{50}, 57 \%$ at five years when adjuvant chemotherapy with a 5 -fluorouracil and leucovorin regimen is added ${ }^{51}$, and $72.9 \%$ at six years when oxaliplatin is associated with the previous regimen ${ }^{52}$.

In a non-ideal comparison, it is concluded that patients with CLM may have their chance of being alive at five years reduced by at least $50 \%$. Therefore, liver metastasis are considered the leading cause of morbimortality in these patients ${ }^{12}$, accounting for at least two-thirds of disease-related deaths ${ }^{3}$.

\section{Recommendations}

- Half of all CRC patients will have a metastatic lesion, of which $80 \%$ will affect the liver, and of those, 15 to $30 \%$ will be potentially resectable. Concordance $\mathbf{9 7 \%}$

- Data from INCA and the literature suggests that between 2,445 and 4,890 patients of liver metastases are potentially resectable. Concordance $90 \%$

- Liver metastases are the main cause of death in patients with CRC. Concordance $85 \%$

- Multimodal treatment has the best response, with an increase in overall survival compared to surgery alone. Concordance $92 \%$

Topic 2 - Diagnosis and staging of CLM

Imaging techniques that allow evaluation of liver metastases include ultrasound (US), computed tomography (CT), magnetic resonance (MRI) and positron emission tomography (FDG-PET) ${ }^{53,54}$. The modality of choice is determined by local availability and service experience.

Transabdominal ultrasound 
Despite being a method widely available and inexpensive, it exhibits low sensitivity rates and therefore has limited application in the evaluation of CLM.

The overall sensitivity ranges between $50-77 \%$, but it does not exceed $20 \%$ in lesions smaller than $1 \mathrm{~cm}$.

Its main disadvantages: 1 ) operator-dependent method; 2) limited evaluation in obese patients with bowel distension or non-collaborative subjects.

The use of intravenous contrast (microspheres) increases the sensitivity for detection of focal liver lesions in about $20 \%$, with results similar to those of CT with multidetectors ${ }^{55,56}$. However, this is a recently used technique with limited availability in Brazil.

\section{Computed tomography (CT)}

It is a widely available and relatively low-cost method; currently considered a standard technique for tumor staging, response evaluation and follow-up.

The test should be performed in a multidetector-computed tomography (MDCT) with a dynamic study using intravenous iodinated contrast.

The limitations/disadvantages of the technique include exposure to ionizing radiation, risk of anaphylactic reactions to iodinated contrast and renal failure potential.

The main diagnostic limitations are identification and characterization of focal hepatic lesions in livers with fat deposition ${ }^{57,58}$ and of sub-centimeter lesions ${ }^{59,60,61}$.

\section{Magnetic resonance imaging (MRI)}

It is the most accurate imaging technique for the detection and characterization of focal liver lesions. However, costs are higher and it has restricted availability. Other limitations include magnetic field exposure and gadolinium use restrictions in patients with renal insufficiency.

The test may be performed using 1.5 or 3 Tesla equipment and the protocol should include sequences weighted in T1, T2 Diffusion (DWI) and volumetric T1 (3D) with dynamic study after contrast.

Dynamic study is usually performed with the administration of an extracellular distribution of gadolinium chelate, a hepatobiliary agent (disodium gadoxetato), that is available for use in Brazil. The hepatobiliary agent increases the detection rate of liver metastases ${ }^{62}$

Retrospective studies and recent meta-analyzes have demonstrated the superiority of MRI in the evaluation of liver metastases of colorectal carcinoma: 1) MRI showed superior sensitivity to TC both in analysis per patient (81.1 to $88.2 \%$ vs. 74.8 to $83.6 \%$ ) and in analysis per lesion ( 80.3 to $86.3 \%$ vs. 74.4 to $82.6 \%$ ); such superiority is related to higher detection of lesions smaller than $\left.1 \mathrm{~cm}^{57,58} ; 2\right) \mathrm{MRI}$ with conventional study + DWI + hepatobiliary contrast is the most sensitive and specific method for the characterization of LMCRC, especially in lesions smaller than $1 \mathrm{~cm}$ (sensitivity $94 \%$ and specificity $95 \%)^{63,64,65}$; 3) combined use of DWI and dynamic study with disodium gadoxetato significantly increases the diagnostic performance of $\mathrm{MRI}$, with a detection rate higher than the isolated techniques $64,65,66,67$; 4) MRI with hepatobiliary contrast has greater accuracy than FDG-PET/CT in detection of small liver metastases $(92 \% \text { vs. } 60 \%)^{68}$.

In a multicenter randomized prospective study, the performance of MRI with hepatobiliary contrast was superior to $\mathrm{CT}$ with iodinated contrast and MRI with extracellular gadolinium as first-line method in the initial evaluation of LMCRC ${ }^{69}$.

\section{Positron emission tomography with fluorine-18 deoxyglucose} (FDG-PET)

It displays a very high sensitivity and specificity in the detection of liver metastases, with rates near $95 \%$. Furthermore, it is useful to identify extra-hepatic metastases and local recurrence. However, its application is restricted due to low availability and high cost.
The main diagnostic limitations are in the detection of small pulmonary nodules and small liver metastases after chemotherapy ${ }^{57,58,68}$.

Some studies have shown that in patients eligible for surgical resection of MHCR, FDG-PET/CT can identify extra-hepatic sites of metastases undetected by other methods, altering the therapeutic plan ${ }^{70,71,72}$. However, in a recent randomized clinical trial there was no significant change observed in surgical intent with the use of FDG-PE /CT compared to isolated $\mathrm{MDCT}^{73}$.

\section{Intraoperative ultrasound (IOUS)}

IOUS combined with surgical exploration is the gold standard method for detection of liver metastases and often alters the initial surgical plan ${ }^{74}$.

It is an operator-dependent method and should be performed by a radiologist or surgeon experienced in the technique, using an intraoperative probe $(5-12 \mathrm{MHz})$. In a study of 250 patients with preoperative evaluation performed with helical CT, IOUS detected additional hepatic lesions in $27 \%$ of patients ${ }^{75}$. Currently, even with the routine use of MDCT, benefits of IOUS are still observed, with changes to surgery in up to $20 \%$ of cases $^{76,77}$.

\section{Evaluation of systemic treatment response}

The evaluation of response by imaging methods can be performed based on the following perspectives:

\section{Dimensional criteria}

The RECIST guideline criteria (version 1.1) is the most commonly used model for the evaluation of solid tumor response ${ }^{78}$.

\section{Morphologic criteria}

It was proven to be valid in cases of targeted therapy with bevacizumab. However, it was described in a study with high quality MDCT performed in a specialized center, and has yet to be validated in independent studies ${ }^{79}$.

\section{Functional methods}

There is not enough evidence to support the routine use of FDG-PET and other functional techniques such as MRI with diffusion in CLM response evaluation ${ }^{80}$.

\section{Recommendations}

- MDCT with contrast-enhanced is the imaging method of choice for tumor staging, response evaluation and follow-up. For the initial evaluation of liver metastases, the use of MDCT or MRI is recommended, depending on the availability and service experience. Concordance $99 \%$

- MR with DWI and hepatobiliary contrast is the best diagnostic technique for evaluation of liver metastases. When available, current evidence supports its use as a modality of choice in CLM pre-surgical planning. Concordance $\mathbf{7 6 \%}$

- Controversial results exist in regards to the impact of FDG-PET/CT in planning resection of liver metastases. Consider it for patients in whom the identification of extrahepatic disease can modify the treatment plan. Concordance $83 \%$

- Despite advances in preoperative imaging techniques, IOUS combined with manual palpation of the liver is the gold standard for detection of liver metastases. Concordance $\mathbf{8 9} \%$

- RECIST guideline version 1.1 remains the standard criteria for evaluating response, which should be performed using the same initial staging technique. MDCT is recommended for follow-up. Concordance $\mathbf{8 9 \%}$ 
Topic 3 - Definition of respectability

How to estimate the mass/function of the future liver remnant

Liver volumetry

The literature shows overlapping results in terms of residual liver mass estimate when compared to tomography and magnetic resonance. Ultrasonography has limitations inherented to the method, such as the interobserver variability. $\mathrm{CT}$ and MRI have shown similar results, but there are many more studies with $\mathrm{CT}$, with further validated results ${ }^{81}$. Emphasis should be made to the correlation with volume measured in imaging and surgical weight of the resected liver, as it appears that both methods underestimate this result. The calculation of hepatic volume by CT and MRI is accurate and recommended for surgical planning, with similar results, using different correction factors $^{82}$. CT - correction factor: 0.85; MRI - correction factor: 0.78 . The main cause of discrepancy between liver volume calculated by CT and ex-vivo volume is blood perfusion and should be considered an overestimation in the order of $13 \%^{83}$. Hepatic volume by CT performed manually or automatically correlates strongly with actual liver volume. The automated way is faster ${ }^{84}$. Open and free software programs can be used by the surgeon to calculate the hepatic volume by $\mathrm{CT}$ with similar results to those obtained by the radiologist using dedicated software at workstations ${ }^{85}$.

Importantly, the estimates are only based on percentage of liver volume and are subject to limitation and should be viewed critically, especially in patients with hepatic steatosis/ obesity and long courses of chemotherapy in the past. Some formulas have been developed and validated in search of greater security and should be used with caution especially in patients after portal vein embolization with modest growth ${ }^{86}$.

Anatomic, biological and clinical criteria of resectability Resectability should be defined by an experienced surgeon in liver surgery ${ }^{87}$. The anatomical resection criteria include: complete resection of the tumor, absence of residual tumor preserving at least one hepatic vein, homolateral maintenance to the portal pedicle and future live remnant $>20 \%{ }^{88}$. The recommended minimum margin at the time of resection is the macroscopic free margin. Positive microscopic margin can be accepted as an adverse finding in the postoperative period, but should not be offered as an option if imaging exams suggest that result ${ }^{89,90}$. R1 surgery offers survival similar to $\mathrm{R} 0$ resection in selected studies but it is still controversial ${ }^{91}$.

A careful clinical evaluation should precede any liver surgery, particularly in patients with many comorbidities or the elderly. Note that resections in elderly patients over 70 years had similar results to those under 70 years old, with higher morbimortality in the first 90 days ${ }^{92}$. There are no studies that define the biological and clinical factors that represent criteria for resectability, but they are important prognostic factors and should be taken into consideration. They are: KRAS, NRAS, BRAF, CA 19-9, CEA, response to chemotherapy, number, size and location of metastases, synchronous or metachronous disease, presence of extrahepatic lesions, neutrophil-to-lymphocyte ratio, hypoechoic lesion on ultrasound, hTERT expression, disease-free interval, surgical margins, repeated resections ${ }^{93,94}$

\section{Strategies to increase respectability}

Preoperative portal vein embolization (PPVE)

Percutaneous PPVE increases the contralateral lobe with low complication rate and virtually no mortality for the procedure. The hepatectomy should be performed within three to four weeks after the embolization procedure ${ }^{95}$. Percutaneous PPVE should be indicated before hepatectomy when the surgical plan entails the removal of more than four liver segments and when future liver remnant (FLR) is: $<20 \%$ in patients with normal liver; $<30 \%$ in post-chemotherapy patients and $<40 \%$ in cirrhotic patients ${ }^{13,96}$. Chemotherapy and anti-angiogenic inhibitors do not affect liver regeneration after portal vein embolization, but should be discontinued six weeks before the embolization procedure ${ }^{97}$. Even after PPVE, there is the occurrence of transient liver failure in about $2.5 \%$ of cases and acute liver failure in $1 \%$ of cases of major hepatectomies for colorectal cancer metastases. PPVE does not guarantee resectability, as $15 \%$ of patients fail to be operated on, in most cases due to the progression of neoplastic disease or inappropriate FLR growth ${ }^{95}$.

\section{Two-stage hepatectomy}

The indication of hepatectomy in two stages is uncommon and should be considered in initially unresectable patients with bilobar metastases, in whom resection at one time was not feasible because of insufficient FLR, even with the use of PPVE and ablative therapies. After the first stage of resection, 25\% of patients will fail to reach the second stage due to disease progression in most cases. The second stage has twice the morbimortality of the first stage. Patients who complete the two stages may have similar survival to those who undergo just a single resection in their treatment ${ }^{98,99}$. Some recommendations on the surgical technique should be highlighted as: avoid leaving viable metastasis in FLR after the first stage, using radiofrequency ablation if necessary; avoid dissection of the pedicle in the first stage and mobilization of the lobe to be resected in the second stage ${ }^{100}$; resection of the primary tumor in the first stage in patients with synchronous metastases decreases the number of surgical procedures and facilitates chemotherapy ${ }^{101}$. Chemotherapy in the interval between the first and second stage does not guarantee lower rate of disease progression or a greater chance to complete the second stage $\mathrm{e}^{102}$.

Associating liver partition and portal vein ligation for staged hepatectomy (ALPPS)

The ALPPS strategy must be performed by teams with experience in complex liver surgery ${ }^{103,104,105,106}$. During the stages of ALPPS, the association with major abdominal surgeries should be avoided ${ }^{104}$. The indication for ALPPS is resection with curative intent of large liver tumors with inadequate FLR volume and as an alternative to the classic strategy in two stages, especially as salvage surgery in patients undergoing portal embolization/ ligation with insufficient gain of residual liver mass ${ }^{107,108,109}$. ALPPS is a technical option in patients with portal branch thrombosis that precludes percutaneous embolization ${ }^{103,110}$. The potential for tumor progression in the ALPPS strategy is at least the same as portal embolization ${ }^{111,112,113}$. However, ALPPS results in higher morbimortality rates as well as more severe postoperative complications in both surgical stages ${ }^{103,114,115}$. Hypertrophy of the residual liver provided by ALPPS ( $\pm 75 \%)$ is similar to percutaneous portal embolization that extends to segment IV, and is significantly superior to isolated right portal embolization/ligation ${ }^{115}$.

\section{Radiofrequency associated with resection}

Radiofrequency ablation (RFA) is no substitute for liver resection in the treatment of colorectal liver metastases, even in tumors smaller than $3 \mathrm{~cm}^{116}$. The indication of RFA associated with hepatic resection is rare, but its use occurs in $25 \%$ of patients who require repeated hepatectomy in the course of their treatment, and is associated with increased intrahepatic recurrence ${ }^{117}$. In patients with bilobar metastases where resection was indicated in combination with RFA, recurrence was similar in the ablation site, in wedge resection margin and segmental resection margin. Resection associated with RFA of more than 10 lesions is associated with shorter time to recurrence ${ }^{118}$. One should always seek an ablation area that provides a minimum margin of $1 \mathrm{~cm}$ beyond the tumor. Its ideal use is for tumors up to $3 \mathrm{~cm}$ in surgery, where resection is not viable and/or patients without performance status for surgery and when percutaneous portal vein is preferable. 


\section{Recommendations}

- Anatomic resection criteria:

oComplete resection of all tumors with free margin.

oPreservation of at least one of three hepatic veins.

o Maintenance of the ipsilateral portal pedicle (artery, portal and biliary tract)

oSufficient future liver remnant. Concordance $\mathbf{9 8 \%}$

- CT and/or MRI are recommended for surgical planning, with similar results in terms of assessment of the future liver remnant. Concordance $\mathbf{9 3 \%}$

- Percutaneous preoperative portal embolization should be considered when planning the resection of more than four liver segments that result in $\mathrm{FLR}<20 \%$ in patients with normal liver, $30 \%$ after chemotherapy and $40 \%$ in cirrhotic patients. Concordance $\mathbf{9 5 \%}$

- The indication of two-stage hepatectomy is uncommon and should be considered in initially unresectable patients with bilobar metastases, in whom one-time resection was not feasible because of insufficient FLR, even with the use of PPVE and ablative therapies. Concordance $92 \%$

- Radiofrequency ablation is no substitute for LMCRC even in tumors smaller than $3 \mathrm{~cm}$ and can be used in patients who are not candidates for surgery or associated with resection in multinodular cases. Concordance $\mathbf{9 0 \%}$

- ALPPS is a complex technique to cause hypertrophy of the FLR associated with significant postoperative morbimortality. It can be indicated in selected cases as an alternative to two-stage hepatectomy or after failure of percutaneous embolization portal hypertrophy. It is suggested that it can be performed in specialized centers with a high volume of liver surgery in study protocols. Concordance $96 \%$

Topic 4 - Clinical, pathological and molecular prognostic factors in treatment definition

There are clinical, pathological and molecular factors that can help estimate the prognosis of patients with LMCRC who undergo hepatectomy. These factors can be considered individually or in association with clinical risk scores. They are useful to understand the potential benefits and risks of recurrence, but should not be used to contraindicate surgical resection. Some prognostic factors such as margin, postoperative complications and pathological response to chemotherapy can only help estimate the benefit or risk after surgery.

\section{Age and postoperative complications}

A study of 20,023 stage IV patients recruited in a randomized clinical trial (RCT) carried out by the ARCAD Clinical Trials Program database showed that younger and elderly patients had worse overall survival (OS) and progression-free survival $(P F S)^{119}$. However, this study only analyzed patients treated with first-line palliative chemotherapy without analyzing the subgroup of patients undergoing resection of liver metastases.

In a retrospective study involving 806 patients undergoing hepatectomy in a single French center, $7 \%$ of patients had $\leq 40$ years. Multivariate analysis showed that age $\leq 40$ years was an independent prognostic factor associated with worse PFS ${ }^{120}$.

In the Livermet Survey study with 7,764 patients, $20.9 \%$ were aged $\geq 70$ years. Mortality at 60 days for patients $\geq 70$ years was $3.8 \%$ vs. $1.6 \%$ for younger patients $(p<0.001)$ and 3 -year OS was $57.1 \%$ vs. $60.2 \%(p<0.001)$ respectively ${ }^{121}$. Therefore, resection of liver metastases in older patients has similar results to younger patients, with acceptable mortality.

A meta-analysis of four studies with 2,280 patients showed decreased 5-year DFS (OR 1.98) and OS (OR 1.68) for patients who had postoperative complications ${ }^{122}$

\section{Multiple liver metastases}

The Memorial Sloan Kettering Cancer Center analyzed its database of patients who underwent resection of liver metastases between 1998 and 2002, and from a total of 584 patients, 98 $(17 \%)$ had four or more liver metastases ${ }^{123}$. In this group of patients, median OS was 41 months and 5 -year OS was 33\%. However, median DFS was 14 months, 3-year and 5 year DFS were $12 \%$ and $0 \%$, confirming the high risk of recurrence for patients with four or more liver metastases.

A retrospective Japanese study with 736 patients divided the patients into three groups: group A with 1-3 metastases ( $n=493$ patients), group B with 4-7 metastases $(n=141)$ and group $C$ with eight or more metastases $(n=102)^{124}$. OS at five years was $56 \%$ in group $A, 41 \%$ in group $B$ and $33 \%$ in group C. However, 5 -year RFS was $29 \%$ for group A, $12 \%$ for group B and $1.7 \%$ for group $C$.

\section{Meta-analysis of prognostic factors}

A meta-analysis of survival after liver resection for metastatic colorectal cancer demonstrated a modest predictive relationship with survival; however, seven prognostic factors were significant: positive lymph node in the primary tumor, CEA level, extrahepatic disease, tumor grade, positive margins, more than one liver metastasis and tumor diameter greater than three centimeters ${ }^{125}$. Pooled effect calculated for these seven prognostic factors ranged from 1.52 to 2.02 .

\section{Early relapse in less than six months}

In a retrospective series of the Livermet Survey with 6,025 patients, 2,734 (45.4\%) had recurrence, of which 639 $(10.6 \%)$ had early recurrence ${ }^{126}$. OS at five years was $26.9 \%$ for patients with early recurrence vs. $49.4 \%(p<0.0001)$ for those who did not have it. Multivariate analysis demonstrated that the prognostic factors associated with early recurrence were: T3-4 tumors, synchronous metastases, more than three metastases, positive microscopic margin (R1 resection) and the use of radiofrequency ablation (RFA).

\section{Clinical risk scores}

Clinical risk scores and nomograms are intended to estimate the benefit of liver resection correlated with prognostic factors of survival 127,128,129,130,131,132,133. For example, Fong's liver score criteria are node-positive primary tumors, DFS less than 12 months, more than one node, metastasis larger than five centimeters and CEA above $200 \mathrm{ng} / \mathrm{mL}^{127}$. The presence or absence of each of these factors leads to a score from 0 to 5 , which correlated with with 5-year OS. Most clinical risk scores are rarely used and the lack of external validation of these risk calculations prevent their use in selecting patients eligible for liver resection.

\section{Pathological response to preoperative chemotherapy}

Retrospective studies demonstrate that pathological response to preoperative chemotherapy, with variable definitions of response from one study to another, correlate with improved OS ${ }^{134,135}$.

\section{Resection margins}

Several retrospective studies demonstrate that positive margins are associated with increased risk of recurrence in the surgical margin, but that complete resection and not the millimeter size of the margin is what is more important $89,91,136,137$. A meta-analysis of 18 studies with 4,821 patients showed that negative margins $\geq 1 \mathrm{~cm}$ are superior to negative margins $<1$ $\mathrm{cm}$ in 5 -year OS (46\% vs. $38 \%, \mathrm{p}=0.009)^{138}$.

In a prospective observational study of 2,715 patients, positive margin was defined as the distance between metastasis and the border of resection less than one millimeter and negative margin as margin more than $1 \mathrm{~mm}$. In this study, DFS at three 
years in patients with margin greater than $1 \mathrm{~mm}$ was significantly superior to that of cases with a shorter margin and there was no additional gain in DFS with margins greater than $1 \mathrm{~mm}^{139}$.

KRAS, NRAS and BRAF

KRAS and NRAS are predictors of therapy results with anti-EGFR, but they have a less established role as a prognostic factor in metastatic colorectal cancer $140,141,142$. A retrospective analysis of a study with 202 patients suggests KRAS as a possible prognostic factor after surgery for liver metastases (HR 1.99) ${ }^{134}$. However, BRAF is a strong adverse prognostic factor in metastatic colorectal cancer and also post-metastectomy ${ }^{143,144}$

There is a strong agreement ( $>90 \%$ ) in RAS/BRAF results between primary tumor and metastasis and therefore the test can be done in both biopsies of the primary tumor and in metastases biopsies ${ }^{145,146}$.

It is recommended that the report should contain: 1) type of test performed and sensitivity; 2) type of material tested (primary tumor or metastases); 3 ) type of extraction (macro or laser) and the percentage of tumor represented; 4 ) mutated codon and the type of mutation; 5) cut-off used in the laboratory for the interpretation of the results.

\section{Recommendations}

- Prognostic factors, nomograms or clinical risk scores can aid in preoperative patient prognosis assessment but should not interfere in the selection for or against surgery in patients eligible for resection of metastases liver. Concordance $\mathbf{8 6 \%}$

- High CEA $\geq 200 \mathrm{ng} / \mathrm{mL}$, extrahepatic disease, degree of differentiation (indif.), positive margins, more than one liver metastasis, positive lymph nodes (primary tumor), metastasis $>3 \mathrm{~cm}$ and post-operative complications are adverse prognostic factors. Concordance $\mathbf{9 6 \%}$

- Positive surgical margins increase the risk of relapse. Concordance $97 \%$

- It is recommended whenever possible to seek margins $>1$ $\mathrm{cm}$, but that not being possible, free subcentimetric margins are sufficient. Concordance $\mathbf{8 6 \%}$

- Checking the status of mutations in the RAS family is mandatory for patients considered for anti-EGFR therapy. Concordance $97 \%$

\section{CONCLUSION}

Clinical, pathological and molecular prognostic factors with validation were presented to be taken into account in clinical practice.

REFERENCES

1. GLOBOCAN2012. Estimatedcancerincidence, mortalityand prevalence worldwide in 2012. International Agency for Research on Cancer Lyon, France. http://globocan.iarc.fr/Pages/fact_sheets_population aspx. acessado em 19/07/2014.

2. Instituto Nacional deCâncerJoséAlencarGomesdaSilva, Coordenação de Prevenção e Vigilância. Estimativa 2014: Incidência de Câncer no Brasil. Rio de Janeiro: INCA, 2014. http://www.inca.gov.br/ estimativa/2014/estimativa-24042014.pdf.

3. AbdallaEK,Adam R, BilchikAJ, JaeckD, VautheyJN, MahviD. Improving resectability of hepatic colorectal metastases: expert consensus statement. Ann Surg Oncol 2006;13(10):1271-80.
4. Al-Asfoor A, Fedorowicz Z. Resection versus no intervention or other surgicalinterventions for colorectal cancer livermetastases. Cochrane Database Syst Rev 2008;16(2):CD006039.

5. Fong Y, Cohen AM, Fortner JG, Enker WE, Turnbull AD, Coit DG, et al. Liver resection forcolorectal metastases.JClinOncol 1997;15(3):938-46.

6. Sheth KR, Clary BM. Management of hepatic metastases from colorrectal cancer. Clin Colon Rectal Surg 2005;18(3):215-23.

7. Pozzo C, Basso M, Cassano A, Quirino M, Schinzari G, Trigila N, et al. Neoadjuvant treatment of unresectable liver disease with irinotecan and 5 -fluorouracil plus folinic acid in colorrectal cancer patients. Ann Oncol 2004:(15):933-9.

8. Manfredi S, Lepage C, Hatem C, Coatmeur O, Faivre J, Bouvier AM. Epidemiology and management of liver metastases from colorectal cancer. Ann Surg 2006;244(2):254-9

9. Welch JP, Donaldson GA. The clinical correlation of an autopsy study of recurrent colorectal cancer. Ann Surg 1979;189(4):496-502.

10. Shindo K. Recurrence of carcinoma of the large intestine. A statistical review. Am J Proctol 1974;25(3):80-90.

11. MantkeR,SchmidtU,WolffS,KubeR, LippertH.Incidenceofsynchronous liver metastases in patients with colorectal cancer in relationship to clinico-pathologic characteristics. Results of a German prospective multicenter observational study. Eur J Surg Oncol 2012;38(3):259-65.

12. Pawlik TM, Shulick $R$, Chot M. Expanding criteria for resectability of colorectal liver metastases. Oncologist 2008;13(1):51-64.

13. Lupinacci RM, Coelho FF, Perini MV, Lobo EJ, Ferreira FG, Szutan LA , et al. Current management of liver metastases from colorectal cancer: recommendations of the São Paulo Liver Club. Rev Col Bras Cir 2013;40(3): 251-60.

14. Ghiringhelli F, Hennequin A, Drouillard A, Lepage C, Faivre J, Bouvier AM. Epidemiology and prognosis of synchronous and metachronous colon cancer metastases: A French population-based study. Dig Liver Dis 2014;46(9):854-8.

15. Zavadsky KE, Lee YT. Liver metastases from colorectal carcinoma: incidence, resectability, and survival results. AmSurg 1994;60(12):929-33.

16. Pugh S, Fuller A, Rose P, Perera-Salazar R, Mellor J, George S, et al What is thetrueincidence ofmetachronouscolorectal livermetástases? Evidence from the UK FACS (follow-up after colorectal surgery) trial. Gut (Medical Abstracts) 2012;61 Suppl 2:A24.

17. Coimbra FJF, Pires TC, Costa Jr WL, Diniz AL, Ribeiro HSC. Avanços no tratamento cirúrgico das metástases hepáticas colorretais. Rev Assoc Med Bras 2011;57(2):220-7.

18. Leporrier J, Maurel J, Chiche L, BaraS, SegolP, Launoy G. A populationbased study of the incidence, management and prognosis of hepatic metastases from colorectal cancer. Br J Surg 2006;93(4):465-74.

19. Hackl C, Gerken M, Loss M, Klinkhammer-Schalke M, Piso P, Schlitt HJ A population-based analysis on the rate and surgical management of colorectal liver metastases in Southern Germany. Int J Colorectal Dis 2011:26(11):1475-81.

20. Kune GA, Kune S, Field B, Wgite R, Brough W, Schellemberger R, et al. Survival in patients with large-bowel cancer. A population-based investigation from the Melbourne Colorectal Cancer Study. Dis Colon Rectum 1990;33(11):938-46.

21. AlleyPG, McNeeRK.Colorectal cancerinAuckland 1981-1982: patients with liver metastases. N Z Med J 1985;98(785):697-9.

22. Bengmark $S$, Hafströn $L$. The natural history of primary and secondary malignant tumor of the liver. The prognosis for patients with hepatic metastases from colonic and rectal carcinoma by laparotomy. Cancer 1969;23(1):198-202.

23. Thomasset SC, Dennison AR, Metcalfe MS, Steward WP, Garcea G Changing trends in the presentation of colorectal liver metastases in a single hepatobiliary tertiary referral centre over fourteen years. Eur J Surg Oncol 2013;39(11)1243-7.

24. Taylorl,MulleeMA, CampbellMJ.Prognosticindexforthedevelopment of liver metastases in patients with colorectal cancer. Br J Surg 1990;77(5):499-501.

25. Murono K, Kitayama J, Tsuno NH, Nozawa H, Kawai K, Sunami E, et al Hepatic steatosis is associated with lower incidence of liver metastasis from colorectal cancer. Int J Colorectal Dis 2013;28(8):1065-72.

26. Li Destri G, Castaing M, Ferlito F, Minutolo V, Di Cataldo A, Puleo S. Rarehepatic metastases of colorectal cancerin livers with symptomatic HBV and HCV hepatitis. Ann Ital Chir 2013;84(3):323-7.

27. Wang FS, Shao ZG, Zhang JL, Liu YF. Colorectal liver metastases rarely occur in patients with chronic hepatitis virus infection. Hepatogastroenterology 2012;59(117):1390-2.

28. Qiu HB, Zhang LY, Zeng ZL, Wang ZQ, Luo Hy, Keshari RP, et al. HBV infection decreases risk of liver metastasis in patients with colorectal cancer: A cohort study. World J Gastroenterol 2011;17(6):804-8. 
29. Augustin G, Bruketa T, Korolija D, Milosevic M. Lower incidence of hepatic metastases of colorectal cancer in patients with chronic liver diseases:meta-analysis. Hepatogastroenterology2013;60(125):1164-8.

30. Kopetz S, Chang GJ, Overman MJ, Eng C, Sargent DJ, Larson DW et al. Improved survival in metastatic colorectal cancer is associated with adotion of hepatic resection and improved chemotherapy. J Clin Oncol 2009:27(22):3677-83.

31. Pedersen IK, Burcharth F, Roikjaer O, Baden H. Resection of liver metastases from colorectal cancer. Indications and results. Dis Colon Rectum 1994;37(11):1078-82.

32. Nordlinger B, Sorbye $H$, Glimelius B, Poston GJ, Schlag PM, Rougier P et al. Perioperative chemotherapy with FOLFOX4 and surgery versus surgery alone for resectable liver metastases from colorectal cancer (EORTC Intergroup trial 40983): a randomised controlled trial. Lancet 2008;371(9617):1007-16.

33. Ciliberto D, Prati U, Roveda L, Barbieri V, Staropoli N, Abbruzzese $A$, et al. Role of systemic chemotherapy in the management of resected or resectable colorectal liver metastases: a systematic review and meta-analysis of randomized controlled trials. Oncol Rep 2012;27(6):1849-56.

34. Adam R, Avisar E, Ariche A, Giachetti S, Azoulay D, Castaing D, et al. Five-year survival following hepatic resection after neoadjuvant therapyfornonresectablecolorectal.AnnSurg Oncol2001;8(4):347-53.

35. Adam R, Delvart V, Pascal G, Valeanu A, Castaing D, Azoulay D, et al. Rescuesurgeryforunresectablecolorectallivermetastases downstaged by chemotherapy. Ann Surg 2004; 240(4):644-658.

36. Ardito F, Vellone M, Cassano A, De Rose AM, Pozzo C, Coppola A, et al. Chance of cure following liver resection for initially unresectable colorectal metastases: analysis of actual 5-year survival. J Gastrointest Surg 2013;17(2):352-9.

37. Falcone A, Ricci S, Brunetti I, Pfanner E, Allegrini G, Barbara C, et al. Phase III trial of infusional fluorouracil, leucovorin, oxaliplatin, and irinotecan (FOLFOXIRI) compared with infusional fluorouracil, leucovorin, and irinotecan (FOLFIRI) as first-line treatment for metastatic colorectal cancer: the gruppo oncologico nord ovest. J Clin Oncol 2007;25(13):1670-6.

38. Folprecht $G$, Gruenberger $T$, Bechstein WO, Raab HR, Lordick F, Hartmann JT, et al. Tumour response and secondary resectability of colorectal liver metastases following neoadjuvant chemotherapy with cetuximab: the CELIM randomised phase 2 trial. Lancet Oncol 2010;11(1):38-47.

39. Ye LC, Liu TS, Ren L, WeiY, Zhu DX, Zai SY, et al. Randomized controlled trial of cetuximab plus chemotherapy for patients with Kras wildtype unresectable colorectal liver-limited metastases. J Clin Oncol 2013;31(16):1931-8.

40. Douillard JY, Siena S, Cassidy J, Tabernero J, Burkes R, BarugelM, et al. Randomized, phaselll trial of panitumumabwith infusional fluorouracil, leucovorin, and oxaliplatin (FOLFOX4) versus FOLFOX4 alone as first-line treatment in patients with previously untreated metastatic colorectal cancer: the PRIMEStudy. JClin Oncol2010:28(31):4697-705.

41. Venook AP, Weiser MR, Tepper JE. Colorectal cancer: all hands on deck. Am Soc Clin Oncol Educ Book 2014:83-9

42. Heinemann $V$, von Weikersthal LF, Decker T, Kiani A, Vehling-Kaiser U, Al-Batran SE, et al. FOLFIRI plus cetuximab versus FOLFIRI plus bevacizumab as first-line treatment for patients with metastatic colorectal cancer (FIRE-3): a randomised, open-label, phase 3 trial. Lancet Oncol 2014;15(10)1065-75.

43. MoertelCG, Fleming TR, MacdonaldJS, HallerDG, LaurieJA, Goodman PJ, et al. Levamisole and Fluorouracil for adjuvante therapy of resected colon carcinoma. N Engl J Med 1990;322(6):352-8.

44. Wolmark N, Rockette H, Mamounas E, Jones J, Wieand S, Wickerhm, et al. Clinical trial to assess the relative efficacy of fluorouracil and leucovorin, fluorouracil and levamisole, and fluorouracil, leucovorin, and levamisole in patients with Dukes' B and C carcinoma of the colon: results from National Surgical Adjuvant Breast and Bowel Project C-04. J Clin Oncol 1999;17(11):3553-9.

45. André T, Boni C, Navarro M, Taberno J, Hickish T, Topham C, et al Improved overall survival with oxaliplatin, fluorouracil, and leucovorin as adjuvant treatment in stage II or III colon cancer in the MOSAIC trial. J Clin Oncol 2009:27(19):3109-16.

46. National Comprehensive Cancer Network Clinical Practice Guidelines in Oncology. Colon Cancer (Version 1.2012). http://www.nccn.org/ professionals/physician_gls/pdf/colon.pdf. April 2012

47. National Comprehensive CancerNetwork Clinical Practice Guidelines in Oncology. Rectal Cancer (Version 1.2012). http://www.nccn.org/ professionals/physician_gls/pdf/rectal.pdf. Jan 2012.
48. Konopke R, Kersting S, Bergert H, Bloomenthal A, Gastmeier J, Saeger, etal.Contrast-enhancedultrasonographyto detectlivermetastases: a prospectivetrial to comparetranscutaneousunenhancedand contrastenhanced ultrasonography in patients undergoing laparotomy. Int J Colorectal Dis 2007;22(2):201-7.

49. Larsen LP, Rosenkilde M, Christensen H, Bang N, Bolvig L, Christiansen $\mathrm{T}$, et al. The value of contrast enhanced ultrasonography in detection of liver metastases from colorectal cancer: a prospective doubleblinded study. Eur J Radiol 2007;62(2):302-7.

50. Floriani I, Torri V, Rulli E, Garavaglia D, Compagnoni A, Salvolini L, et al. Performance of imaging modalities in diagnosis of liver metastases from colorectal cancer:a systematic reviewand meta-analysis.J Magn Reson Imaging 2010; 31(1):19-31.

51. Niekel MC, Bipat S, Stoker J. Diagnostic imaging of colorectalliver metastases with CT, MR imaging, FDG PET, and/or FDG PET/CT: a meta-analysis of prospective studies including patients who have notpreviously undergonetreatment. Radiology2010;257(3):674-84.

52. Kamel IR, Fishman EK. Recent advances in CT imaging of liver metastases. Cancer J. 2004; 10(2):104-20.

53. Soyer P, Poccard M, Boudiaf M, Abitbol M, Hamzi L, Panis $Y$, et al. Detection of hypovascular hepatic metastases at triple-phase helical CT: sensitivity of phases and comparison with surgical and histopathologic findings. Radiology 2004;231(2):413-20.

54. Schwartz LH, Gandras EJ, Colangelo SM, Ercolani MC, Panicek DM. Prevalence and importance of small hepatic lesions found at CT in patients with cancer. Radiology 1999;210(1):71-4.

55. Chen L, Zhang J, Zhang L, Bao J, Liu C, Xia Y, et al. Meta-Analysis of Gadoxetic Acid Disodium (Gd-EOB-DTPA)-Enhanced Magnetic Resonance Imaging for the Detection of Liver Metastases. PLoS One 2012;7(11):e48681

56. Löwenthal D, Zeile M, Lim WY, Wybranski C, Fischbach F, Wieners G, et al. Detection and characterisation of focal liver lesions in colorectal carcinoma patients: comparison of diffusion-weighted and Gd-EOBDTPA enhanced MR imaging. Eur Radiol 2011;21(4):832-40.

57. Shimada K, Isoda H, Hirokawa $Y$, Arizono S, Shibata T, Togashi H. Comparison of gadolinium-EOB-DTPA-enhanced and diffusionweighted liver MRI for detection of small hepatic metastases. Eur Radiol 2010;20(11):2690-8.

58. KohDM, CollinsDJ,Wallace T, Chau I, RiddellAM.Combining diffusionweighted MRI with Gd-EOB-DTPA-enhanced MRI improves the detection of colorectal livermetastases. BrJ Radiol2011;85(1015):980-9.

59. GandhiSN,BrownMA, WongJG,AguirreDA, SirlinCB.MRcontrastagents forliverimaging: what, when, how. Radiographics2006;26(6):1621-36.

60. Hammerstingl R, Huppertz A, Breuer J, Balzer T, Blakeborough A, Carter $\mathrm{R}$, et al. Diagnostic efficacy of gadoxetic acid (Primovist)enhanced MRI and spiral CT for a therapeutic strategy: comparison with intraoperative and histopathologic findings in focal liver lesions. Eur Radiol 2008;18(3)457-67.

61. Seo HJ, Kim MJ, Lee JD, Chung WS, Kim YE. Gadoxetate disodiumenhanced magnetic resonance imaging versus contrast-enhanced 18F-fluorodeoxyglucose positron emission tomography/computed tomography for the detection of colorectal liver metastases. Invest Radiol 2011;46(9):548-55

62. Zech CJ, Korpraphong P, Huppertz A, Denecke T, Kim MJ, Tanomkiat $W$, et al. Randomized multicentre trial of gadoxetic acid-enhanced MRI versus conventional MRI or CT in the staging of colorectal cancer liver metastases. Br J Sueg 2014;101(6):613-21.

63. Erturk SM, Ichikawa T, Fujii H, Yasuda S, Ros PR. PET imaging for evaluation of metastatic colorectal cancer of the liver. Eur J Radiol 2006;58(2):229-35

64. Chua SC, Groves AM, Kayani I, Menezes L, Gacinovic S, Du Y, et al The impact of 18F-FDG PET/CT in patients with liver metastases. Eur J Nucl Med Mol Imaging 2007;34(12):1906-14.

65. Glazer ES, Beaty K, Abdalla EK, Vauthey JN, Curley SA. Effectiveness of positronemissiontomographyforpredicting chemotherapyresponse in colorectal cancer liver metastases. Arch Surg 2010;145(4):340-45.

66. Moulton CA, Gu CS, Law CH, Tandan VR, Hart R, Quan D, et al. Effect of PET Before Liver Resection on Surgical Management for Colorectal Adenocarcinoma Metastases - A Randomized Clinical Trial. JAMA 2014;311(18):1863-9.

67. Cervone A, Sardi A, Conaway GL. Intraoperative ultrasound (IOUS) is essential in the management of metastatic colorectal liver lesions. Am Surg 2000;66(7):611-5.

68. Scaife CL, Ng CS, Ellis LM, Vauthey JN, Charnsangavej C, Curley SA Accuracy of preoperative imaging of hepatic tumors with helical computed tomography. Ann Surg Oncol 2006;13(4):542-6.

69. Ellsmere J, Kane R, Grinbaum R, Edwards M, Schneider B, Jones D. Intraoperative ultrasonography during planned liver resections: why are we still performing it? Surg Endosc 2007;21(8):1280-3. 
70. SahaniDV, KalvaSP, Tanabe KK, HayatSM, O`Neill MJ, HalpernEF, etal. Intraoperative US in patients undergoing surgery for liver neoplasms: comparison with MR imaging. Radiology 2004;232(3):810-4.

71. TherasseP, ArbuckSG, EisenhauerEA, WandersJ, KaplanRS, Rubinstein $\mathrm{L}$, et al. New guidelines to evaluate the response to treatment in solid tumors. European Organization for Research and Treatment of Cancer, National Cancer Institute of the United States, National Cancer Institute of Canada. J Natl Cancer Inst 2000;92(3):205-16.

72. ChunYS, VautheyJN, BoonsirikamchaiP,MaruDM, KopetzS, Palavecino $\mathrm{M}$, etal.Association of computed tomographymorphologic criteriawith pathologic responseand survival in patients treated with bevacizumab for colorectal liver metastases. JAMA 2009;302(21):2338-44.

73. Figueiras RG, Goh V, Padhani AR, Naveira AB, Caamaño AG, Martin CV. The role of functional imaging in colorectal cancer. AJR Am J Roentgenol 2010;195(1):54-66.

74. D'Onofrio M, De Robertis R, Demozzi E, Crosara S, Canestrini S, Pozz Mucelli R. Liver volumetry: Is imaging reliable? Personal experience and review of the literature. World J Radiol 2014;6(4):62-71.

75. KarloC, ReinerCS, StolzmannP, Breitenstein S,MarincekB, WeishauptD, FrauenfelderT.CT-andMRI-basedvolumetry of resected liverspecimen: comparison to intraoperative volume and weight measurements and calculation of conversion factors. Eur J Radiol 2010;75(1): e107-11.

76. NiehuesSM,UngerJK, MalinowskiM, NeymeyerJ,HammB,Stockmann $M$. Liver volume measurement: reason of the difference between in vivo CT-volumetry and intraoperative ex vivo determination and how to cope it. Eur J Med Res 2010;15(8): 345-50.

77. LucianiA, Rusko L, PichonE, LozeB, DeuxJF, LaurentA, etal.Automated liver volumetry in orthotopic liver transplantation using multiphase acquisitions on MDCT. Am J Roentgenol 2012;198(6): w568-74

78. Dello SA, Stoot JH, Van Stiphout RS, Bloemen JG, Wigmore SJ, Dejong

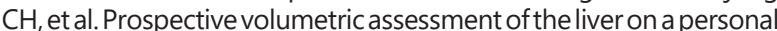
computer by nonradiologists prior to partial hepatectomy. World J Surg 2011;35(2):386-92

79. Ribero D, Chun YS, Vauthey JN. Standardized liver volumetry for portal vein embolization. Semin Intervent Radiol 2008;25(2):104-9

80. Jones RP, Vauthey JN, Adam R, Rees M, Berry D, Jackson R, et al. Effect of specialist decision-making on treatment strategies for colorectal liver metastases. Br J Surg. 2012;99(11):1263-9.

81. ShahA,Alberts S,AdamR.Accomplishmentsin2007intheManagement of Curable Metastatic Colorectal Cancer. Gastrointestinal Cancer Research 2008;2(3):S13-8.

82. PawlikTM, Scoggins CR, Zorzi D, Abdalla EK, Adres A, Eng C, etal. Effect of surgical marginstatus on survival and site of recurrence afterhepatic resection for colorectal metastases. Ann Surg 2005;241(5):715-24.

83. Are C, Gonen M, Zazzali K, Dematteo RP, Jarnagin WR, Fong Y, et al. The impact of margins on outcome after hepatic resection for colorectal metastasis. Ann Surg 2007;246(2):295-300

84. De Haas RJ, Wicherts DA, Flores E, Azoulay D,Castaing D, Adam R. Resection by necessity for colorectal lier metastases. Is it still a contraindication to surgery? Ann Surg 2008;248(4):626-37.

85. Cook EJ, Welsh FK, Chandrakumaran K, John TG, Rees M. Resection of colorectal liver metastases in the elderly: does age matter? Colorectal Dis 2012;14(10):1210-6.

86. Frankel TL, D'Angelica TL. Hepatic resection for colorectal metastases J Surg Oncol 2014;109(1):2-7.

87. Evrard S. Limits of colorectal liver metastases resectability: how and why to overcome them? Recent Results Cancer Res 2014;203:213-29.

88. Abulkhir A, Limongelli $P$, Healey AJ, Damrah O, Tait P, Jackson J, et al. Preoperative portal vein embolization for major liver resection: a meta-analysis. Ann Surg 2008;247(1):49-57

89. May BJ, Talenfeld AD, MadoffDC. Update on portalvein embolization: evidence-based outcomes, controversies, and novel strategies. J Vasc Interv Radiol 2013;24(2):241-54

90. Zorzi D, Chun YS, MadoffDC, Abdalla EK, Vauthey JN. Chemotherapy with bevacizumab does not affect liver regeneration after portal vein embolization in the treatment of colorectal liver metastases. Ann Surg Oncol 2008;15(10): 2765-72.

91. Chua TC, Liauw W, Chu F, Morris DL. Summary outcomes of twostage resection for advanced colorectal liver metastases. J Surg Oncol. 2013;107(2):211-6.

92. Lam VW, Laurence JM, Johnston E, Hollands MJ, Pleass HC, Richardson AJ. A systematic review of two-stage hepatectomy in patients with initially unresectable colorectal liver metastases. HPB (Oxford) 2013:15(7):483-91.
93. Jaeck D, Pessaux P. Bilobar colorectal liver metastases: treatment options. Surg Oncol Clin N Am 2008;17(3):553-68.

94. Karoui M, Vigano L, Goyer P, Ferrero A, Luciani A, Aglietta M, et al. Combined first-stage hepatectomy and colorectal resection in a two-stage hepatectomy strategy for bilobar synchronous liver metastases. Br J Surg 2010;97(9):1354-62.

95. Muratore A, Zimmitti G, Ribero D, Mellano A, Viganò L, Capussotti L. Chemotherapy between the first and second stages of a two-stage hepatectomy for colorectal liver metastases: should we routinely recommend it? Ann Surg Oncol 2012;19(4):1310-5

96. Nadalin S, Capobianco I, Li J, Girotti P, Königsrainer I, Königsrainer A Indications and limits for associating liver partition and portal vein ligation for staged hepatectomy (ALPPS). Lessons Learned from 15 cases at a single centre. Z Gastroenterol 2014;52(1):35-42

97. Alvarez FA, Ardilles V, Sanchez Claria R, Pekolj J, De Santibañes E. Associating liverpartitionand portalvein ligationforstaged hepatectomy (ALPPS): tips and tricks. J Gastrointest Surg 2013 Apr;17(4):814-21.

98. Donatti M, Stavrou GA, Oldhafer KJ. Current position of ALPPS in the surgicallandscape ofCRLMtreatment proposals. World J Gastroenterol 2013:19(39):6548-54

99. Aloia T, Vauthey JN. Associating liver partition and portal vein ligation for staged hepatectomy (ALPPS): what is gained and what is lost? Ann Surg 2012;256(3): e9.

100. Tschuor Ch, Croome KP, Sergeant G, Cano V, Schadde E, Ardiles V, et al. Salvage parenchymal liver transection for patients with insufficient volume increase after portal vein occlusion - an extension of the ALPPS approach. Eur J Surg Oncol 2013;39(11):1230-5

101. Gauzolino R, Castagnet M, Blanieuil ML, Richer JP. The ALPPS technique for bilateral colorectal metastases: three "variations on a theme". Updat Surg 2013;65(2):141-8.

102. Björnsson B, Gasslander T, Sandström P. In situ split of the liver when portal venous embolization fails to induce hypertrophy: a report of two cases. Case Rep Surg 2013;2012:238675.

103. Cavaness KM, Doyle MB, Lin Y, Maynard E, Chapman WC. Using ALPPS to induce rapid liver hypertrophy in a patient with hepatic fibrosis and portal vein thrombosis. J Gastrointest Surg 2013;17(1):207-12.

104. Oldhafer KJ, Donati M, Jenner RM, Stang A, Stavrou GA. ALPPS for patients with colorectal liver metastases: effective liver hypertrophy, but early tumor recurrence. World J Surg 2014;38(6):1504-9.

105. Fukami Y, Kurumiya Y, Kobayashi S. Associating liver partition and portal vein ligation for staged hepatectomy (ALPPS): an analysis of tumor activity. Updates Surg 2014;66(3):223-5.

106. Andriani OC. Long-term results with associating liver partition and portal vein ligation for staged hepatectomy (ALPPS). Ann Surg 2012;256(3):e5.

107. Schadde E, Ardiles V, Slankamenac K, Tschor C, Sergeant G, Amacker $\mathrm{N}$, et al. ALPPS offers a better chance of complete resection in patients with primarily unresectable livertumors compared with conventionalstaged hepatectomies: results of a multicenter analysis.World J Surg 2014:38(6):1510-9

108. Shindoh J, Vauthey JN, Zimmitti G, Curley SA, Huang SY, Mahvash A, et al. Analysis of the Efficacy of Portal Vein Embolization for Patients with Extensive Liver Malignancy and Very Low Future Liver Remnant Volume, Including a Comparison with the Associating Liver Partition with Portal Vein Ligation for Staged Hepatectomy Approach. J Am Coll Surg 2013;217(1):126-34.

109. Stang A, Fischbach R, Teichmann W, Bokemeyer C, Braumann D. A systematic review on the clinical benefit and role of radiofrequency ablation as treatment of colorectal liver metastases. Eur J Cancer 2009;45(10):1748-56.

110. Gleisner AL, Choti MA, Assumpcao L, Nathan H, Schulick RD, Pawlik TM. Colorectal liver metastases: recurrence and survival following hepatic resection, radiofrequency ablation, and combined resectionradiofrequency ablation. Arch Surg 2008;143(12): 1204-12.

111. Eltawil KM, Boame N, Mimeault R, Shabana W, Balaa FK, Jonker DJ, et al. Patterns of recurrence following selective intraoperative radiofrequencyablationasanadjuncttohepatic resectionforcolorectal liver metastases. J Surg Oncol. 2014;110(6):734-8.

112. Lieu CH, Renfro LA, de Gramont A, Meyers JP, Maughan TS, Seymour MT, et al. Association of Age With Survival in Patients With Metastatic Colorectal Cancer: Analysis From the ARCAD Clinical Trials Program. J Clin Oncol 2014;32(27):2975-82. 
113. de Haas RJ, Wicherts DA, Salloum C, Andreani P, Sotirov D, Adam $\mathrm{R}$, et al. Long-term outcomes after hepatic resection for colorectal metastases in young patients. Cancer 2010;116(3):647-58.

114. Adam R, Frilling A, Elias D, Laurent C, Ramos E, Capussotti $L$, et al. Liver resection of colorectal metastases in elderly patients. Br J Surg 2010;97(3):366-76.

115. Matsuda A, Matsumoto S, Seya T, Matsutani T, Kishi T, Yokoi K, et al. Does postoperative complication have a negative impact on long-term outcomes following hepatic resection for colorectal liver metastasis?: a meta-analysis. Ann Surg Oncol 2013;20(8):2485-92.

116. Kornprat $P$, Jarnagin WR, Gonen $M$, DeMatteo RP, Fong $Y$, Blumgart $\mathrm{LH}$, et al. Outcome after hepatectomy for multiple (four or more) colorectal metastases in the era of effective chemotherapy. Ann Surg Oncol 2007;14(3):1151-60.

117. Saiura A, Yamamoto J, Hasegawa K, Koga R, Sakamoto Y, Hata S, et al. Liver resection for multiple colorectal liver metastases with surgery up-front approach: bi-institutional analysis of 736 consecutive cases. World J Surg 2012;36(9):2171-8.

118. Kanas GP, TaylorA, Primrose JN, LangebergWJ, Kelsh MA, MowatFS, et al. Survival after liver resection in metastatic colorectal cancer: review andmeta-analysis of prognosticfactors. ClinEpediomol2012;4:283-301.

119. Viganò L, Capussotti L, Lapointe R, Barroso E, Hubert C, Giuliante F, et al. Early recurrence after liver resection for colorectal metastases: risk factors, prognosis, and treatment. A LiverMetSurvey-based study of 6,025 patients. Ann Surg Oncol 2014;21(40:1276-86.

120. Fong $Y$, Fortner J, Sun RL, Brennan MF, Blumgart LH. Clinical score for predicting recurrence after hepatic resection for metastatic colorectal cancer: analysis of 1001 consecutive cases. Ann Surg 1999;230(30:309-18.

121. Iwatsuki S, Dvorchik I, Madariaga JR, Marsh JW, Dodson F, Bonham AC, etal. Hepatic resection formetastaticcolorectal adenocarcinoma:a proposal ofaprognosticscoring system.JAmCollSurg 1999;189(3):291-9.

122. Nordlinger B, GuiguetM, VaillantJC, BalladurP, BoudjemaK, Bachellie $P$, et al. Surgical resection of colorectal carcinoma metastases to the liver. A prognostic scoring system to improve case selection, based on 1568 patients. Association Française de Chirurgie. Cancer 1996;77(7):1254-62

123. Reissfelder C, Rahbari NN, Koch M, Ulrich A, Pfeilschifter I, Waltert $A$, et al. Validation of prognostic scoring systems for patients undergoing resection of colorectal cancer liver metastases. Ann Surg Oncol. 2009;16(12):3279-88.

124. Zakaria S, Donohue JH, Que FG, Farnell MB, Schleck CD, Ilstrup DM, et al. Hepatic resection for colorectal metastases: value for risk scoring systems? Ann Surg 2007;246(2):183-91.

125. Kattan MW, Gönen M, JarnaginWR, DeMatteo R, D'Angelica M, Weiser $\mathrm{M}$, etal.Anomogramforpredicting disease-specificsurvivalafterhepatic resectionformetastaticcolorectal cancer.AnnSurg2008;247(2):282-7.

126. Reddy SK, Kattan MW, Yu C, Ceppa EP, de la Fuente SG, Fong Y, et al. Evaluation of peri-operative chemotherapy using a prognostic nomogram for survival after resection of colorectal liver metastases. HPB 2009;11(7):592-9.
127. Adam R, WichertsDA, deHaas RJ, AloiaT, LéviF, PauleB, etal.Complete pathologic response after preoperative chemotherapy for colorectal liver metastases: myth or reality? J Clin Oncol 2008;26(10):1635-41.

128. Blazer DG 3rd, Kishi Y, Maru DM, Kopetz S, Chun YS, Overman $\mathrm{MJ}$, et al. Pathologic response to preoperative chemotherapy: a new outcome end point after resection of hepatic colorectal metastases. J Clin Oncol 2008;26(33):5344-51.

129. Figueras J, Burdio F, RamosE, Torras J, Llado L, Lopez-Ben S, et al. Effect of subcentimeternonpositive resection margin on hepatic recurrence in patients undergoing hepatectomy for colorectal liver metastases. Evidences from 663 liver resections. Ann Oncol 2007;18(7):1190-5.

130. Herman P, Pinheiro RS, Mello ES, Lai Q, Lupinacci RM, Perini MV, et al. Surgical margin size in hepatic resections for colorectal metastasis: impacton recurrence and survival. Arq Bras Cir Dig 2013;26(4):309-14.

131. Dhir M, Lyden ER, Wang A, Smith LM, Ullrich F, Are C. Influence of margins on overall survival after hepatic resection for colorectal metastasis: a meta-analysis. Ann Surg 2011;254(2):234-42.

132. Hamady ZZ, Lodge JP, Welsh FK, Toogood GJ, White A, John T, et al. One-millimeter cancer-free margin is curative for colorectal liver metastases: a propensity score case-match approach. Ann Surg 2014;259(3):543-8.

133. Douillard JY, Oliner KS, Siena S, Tabernero J, Burkes R, Barugel M, et al. Panitumumab-FOLFOX4 treatment and RAS mutations in colorectal cancer. N Engl J Med 2013;369(11):1023-34.

134. Douillard JY, Tabernero J, Siena S, Peeters M, Koukakis R, Terwey $\mathrm{JH}$, et al. Survival outcomes in patients (pts) with KRAS/NRAS (RAS) wild-type (WT) metastatic colorectal cancer (mCRC) and non-liverlimited disease (non-LLD): Data from the PRIME study. J Clin Oncol (Meeting Abstracts) 2014;32 Suppl 15:3550.

135. Ciardiello F, Lenz HJ, Kohne CH, Heinemann V, Tejpar S, Melezinek I, et al. Treatment outcome according to tumor RAS mutation status in CRYSTAL study patients with metastatic colorectal cancer (mCRC) randomized to FOLFIRI with/withoutcetuximab.JClin Oncol(Meeting Abstracts) 2014;32: Suppl 15:3506.

136. Van Cutsem E, Köhne CH, Láng I, Folprecht G, Nowacki MP, Cascinu $\mathrm{S}$, et al. Cetuximab plus irinotecan, fluorouracil, and leucovorin as first-line treatment for metastatic colorectal cancer: updated analysis of overall survival according to tumor KRAS and BRAF mutation status. J Clin Oncol 2011;29(15):2011-9.

137. Yaeger R, CercekA, Chou JF, Sylvester BE, Kemeny NE, Hechtman JF, et al.BRAF mutation predicts forpoor outcomes aftermetastasectomyin patientswithmetastaticcolorectal cancer.Cancer2014;120(15):2316-24.

138. BaasJM,KrensLL, GuchelaarHJ,MorreauH,GelderblomH.Concordance of predictive markers for EGFR inhibitors in primary tumors and metastasesincolorectal cancer:areview. Oncologist2011;16(9):1239-49.

139. Vakiani E, Janakiraman $M$, Shen $R$, Sinha R, Zeng Z, Shia J, et al. Comparative genomicanalysis of primaryversus metastatic colorectal carcinomas. J Clin Oncol 2012;30(24):2956-62. 